05

\title{
Сверхпроводящий контакт для ВТСП-лент второго поколения
}

\author{
() И.В. Куликов, М.Я. Черных, Т.С. Крылова, А.В. Овчаров, И.А. Черных, М.Л. Занавескин \\ Национальный исследовательский центр „Курчатовский институт“, Москва, Россия \\ E-mail: kulikov_iv@nrcki.ru \\ Поступило в Редакцию 12 декабря 2018 г. \\ В окончательной редакции 12 декабря 2018 г. \\ Принято к публикации 10 января 2019 г.
}

\begin{abstract}
Предложен подход для эпитаксиального сращивания лент на основе $\mathrm{GdBa}_{2} \mathrm{Cu}_{3} \mathrm{O}_{7-\delta}$ с использованием слоя $\mathrm{YBa}_{2} \mathrm{Cu}_{3} \mathrm{O}_{7-\delta}$. Изучены структурные и электрические характеристики сформированного контакта. Методом просвечивающей растровой электронной микроскопии исследован поперечный срез области сращивания, показано частичное плавление $\mathrm{YBa}_{2} \mathrm{Cu}_{3} \mathrm{O}_{7-\delta}$, а также твердофазная диффузия с образованием фаз $(\mathrm{Gd}, \mathrm{Y}) \mathrm{Ba}_{2} \mathrm{Cu}_{3} \mathrm{O}_{7-\delta}, \mathrm{Y}_{2} \mathrm{BaCuO}_{5}, \mathrm{BaCuO}_{2}$ и $\mathrm{CuO}$. Продемонстрирована токонесущая способность сверхпроводящего контакта более $30 \%$ от исходного тока ленты.
\end{abstract}

DOI: 10.21883/PJTF.2019.07.47530.17639

В магнитных системах с замороженным потоком широкое применение нашли материалы $\mathrm{NbTi}_{\text {и }} \mathrm{MgB}_{2}$ $\left(\mathrm{NbTi}-9.2 \mathrm{~K}, \mathrm{MgB}_{2}-39 \mathrm{~K}\right)$ [1,2]. Это связано c возможностью создания сверхпроводящего контакта методом холодной сварки для проводов на их основе. Создание электротехнических устройств на базе высокотемпературных сверхпроводящих (ВТСП) лент второго поколения с замороженным магнитным потоком весьма перспективно, однако в настоящее время не существует технологии создания сверхпроводящего контакта на их основе. Для реализации сверхсильных сверхпроводящих магнитов с замороженным магнитным потоком с высокой степенью стабильности необходима разработка технологии создания сверхпроводящего контакта для ВТСП-лент второго поколения.

Эпитаксиальное сращивание ВТСП-лент на основе $R e \mathrm{Ba}_{2} \mathrm{Cu}_{3} \mathrm{O}_{7-\delta} \quad(R e \mathrm{BCO}$, где $R e-$ редкоземельный металл) является сложной технологической задачей. Инконгруэнтное плавление сверхпроводника на основе $R e \mathrm{BCO}$ делает невозможным соединение пленок через жидкофазное сплавление, так как это неминуемо приведет к деградации сверхпроводящих характеристик материала. Таким образом, сращивание пленок сверхпроводника должно происходить либо в режиме твердотельной диффузии, либо в режиме контролируемого подплавления материала. Существуют отдельные публикации, в которых описываются первые результаты по созданию сверхпроводящего контакта между двумя ВТСП-лентами второго поколения за счет соединения лент при высокой температуре под большим механическим давлением в атмосфере кислорода [3]. Парциальное давление кислорода и температура - ключевые параметры создания контакта для обеспечения термодинамической устойчивости $R e B C O$. Одной из существенных проблем является выход кислорода из ВТСП-пленки во время соединения. Для восстановления стехиометрии по кислороду, а следовательно, и сверхпроводящих свойств пленки в работе [4] предложено создание массива отверстий в исходных лентах в области контакта и проведение накислораживающего отжига в течение $350 \mathrm{~h}$ после проведения соединения лент. В [5] предложен способ соединения двух ВТСП-лент через массивный сверхпроводник, имеющий меньшую температуру плавления (пары YBCO-TmBCO, YBCO-ErBCO, GdBCO-YBCO) [6,7]. Существенным недостатком данного подхода являются большие геометрические размеры соединения. Необходим дальнейший поиск путей создания сверхпроводящего контакта, характеризующихся высокой технологичностью, воспроизводимостью и простотой реализации. В настоящей работе предлагается метод создания сверхпроводящего контакта ВТСП-лент второго поколения на основе $\mathrm{GdBCO}$ через осажденный тонкий слой YBCO, служащий „сплавляющим“ материалом.

Для создания контакта были использованы специально подготовленные ВТСП-ленты. Сверхпроводящие слои $\mathrm{GdBCO}$ и $\mathrm{YBCO}$ толщиной $450 \mathrm{~nm}$ и $55 \mathrm{~nm}$ соответственно были сформированы методом импульсного лазерного осаждения на лентоперемоточной установке PLD T1000 (PVD Products). Осаждение осуществлялось на подложки с буферными слоями Hastelloy/ $\mathrm{Al}_{2} \mathrm{O}_{3} / \mathrm{Y}_{2} \mathrm{O}_{3} / \mathrm{MgO} / \mathrm{LaMnO}_{3}$. Был использован эксимерный лазер LEAP 130 (Coherent), работающий на газовой смеси $\mathrm{XeCl}$, с длиной волны $308 \mathrm{~nm}$, энергией импульса $600 \mathrm{~mJ}$, частотой следования импульсов $200 \mathrm{~Hz}$. Защитный слой серебра толщиной $1 \mu \mathrm{m}$ был сформирован методом термовакуумного распыления. Токонесущая способность ленты, определенная по критерию $1 \mu \mathrm{V} / \mathrm{cm}$, составила $104 \mathrm{~A} / 12 \mathrm{~mm}$ ширины. Структурные характеристики полученных пленок были исследованы методом рентгеноструктурного анализа (PCA) на установке SmartLab (Rigaku) в режиме $\theta-2 \theta$-сканирования. Исследование поперечного среза области контакта методом просвечивающей растровой электронной микроскопии (ПРЭМ) проводилось на микроскопе TITAN 80-300 (FEI). 


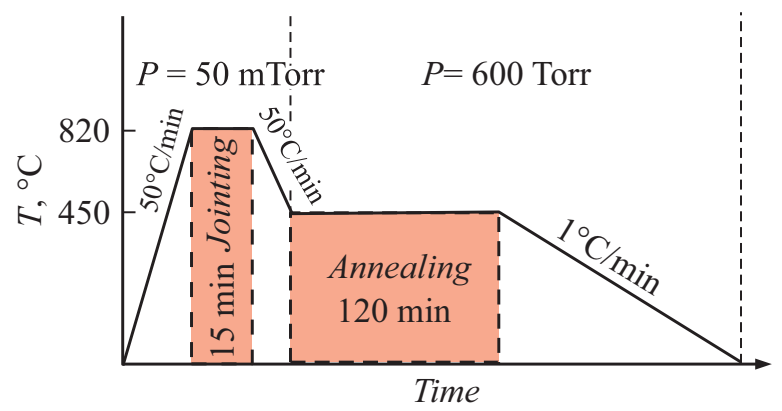

Рис. 1. Цикл термической обработки при эпитаксиальном сращивании ВТСП-лент на основе GdBCO.

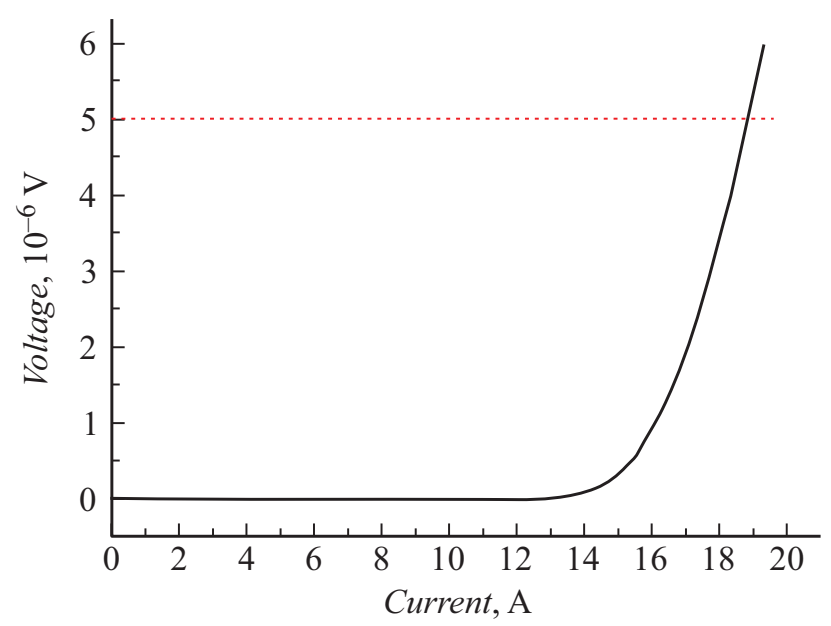

Рис. 2. Вольт-амперная характеристика сверхпроводящего контакта.

Для создания сверхпроводящего контакта исходная лента была разрезана вдоль на две части (с токонесущей способностью $52 \mathrm{~A} / 6 \mathrm{~mm}$ ширины) с помощью волоконного лазера Mars J20 (Han's laser). Перед соединением защитный слой серебра в области эпитаксиального сращивания был стравлен в перекисно-аммиачной смеси $\mathrm{NH}_{4} \mathrm{OH}: \mathrm{H}_{2} \mathrm{O}_{2}: \mathrm{H}_{2} \mathrm{O}(1: 1: 10)$. Создание контакта проводилось путем сжатия двух лент между пластинами из нержавеющей стали (при механическом давлении $\sim 30 \mathrm{MPa}$ ), помещения их в среду кислорода, нагрева до температур, близких к температуре плавления YВСО, и выдержки при этой температуре для обеспечения твердофазной диффузии между сверхпроводящими слоями.

Твердофазная диффузия материалов эффективно применяется для гладких эпитаксиальных пленок, однако сверхпроводящие слои $R e$ ВCO в ВТСП-лентах второго поколения таковыми не являются [8], поэтому для последующего соединения лент необходимо обеспечить частичное плавление сверхпроводящего слоя ҮВСО. Плавление $R e \mathrm{BCO}$ происходит следующим образом [3]:

$$
\begin{aligned}
2 \operatorname{ReBa}_{2} \mathrm{Cu}_{3} \mathrm{O}_{7-\delta} \rightarrow & R e_{2} \mathrm{BaCuO}_{5}+3 \mathrm{BaCuO}_{2}+2 \mathrm{CuO} \\
& +(0.5-\delta) \mathrm{O}_{2} .
\end{aligned}
$$

Реакция является необратимой, сверхпроводимость в области расплава разрушается. Поэтому, с одной стороны, нельзя допустить полного расплавления сверхпроводящего слоя ҮВСО, а с другой стороны, частично подплавляя ҮВСО, мы можем не только увеличить площадь контакта для твердофазной диффузии между ВТСП-пленками, но и повысить механическую прочность контакта, так как при этом жидкие продукты разложения $\mathrm{YBCO}\left(\mathrm{CuO}\right.$ и $\left.\mathrm{BaCuO}_{2}\right)$ заполняют пустоты и полости.

Еще одним условием успешного создания контакта двух ВТСП-лент является подбор условий соединения лент, также обеспечивающих сохранение защитного серебряного слоя, что критически важно при соединении готовых коммерческих лент. Остаточное давление кислорода в камере было выбрано равным $50 \mathrm{mTorr}$; при таком давлении температура плавления серебра превышает температуру плавления ҮВСО [9]. Во избежание выхода кислорода из пленки сверхпроводника необходимо произвести процесс эпитаксиального сращивания как можно быстрее. Цикл термической обработки при эпитаксиальном сращивании ВТСП-лент на основе GdBCO приведен на рис. 1.

При температурах выше $825^{\circ} \mathrm{C}$ происходило испарение серебра и разрушение сверхпроводящего слоя недалеко от сжимающих пластин, так как использовался радиационный нагрев, и температура ленты внутри пластин была меньше, чем температура снаружи. При температурах $T=815-825^{\circ} \mathrm{C}$ соединение ВТСП-лент прошло успешно. Вольт-амперная характеристика контакта без проведения дополнительного отжига имеет резистивный ход. Однако двухчасового накислораживающего отжига хватает для восстановления сверхпроводящих свойств даже без создания массива отверстий, что является неоспоримым преимуществом перед методом сплавления двух ВТСП-лент на основе GdBCO без использования слоя ҮВСО [4].

Для ВТСП-контакта, созданного при использовании выбранного режима (рис. 1), критический ток по критерию $1 \mu \mathrm{V} / \mathrm{cm}$ составил $18 \mathrm{~A}$ (34\% от тока исходной ленты), при этом при нулевом напряжении ток достиг $13 \mathrm{~A}$ (рис. 2). Измерения проводились таким образом, чтобы область контакта находилась между потенциальными контактами, расположенными на расстоянии $5 \mathrm{~cm}$ друг от друга. На рис. 3, $a$ приведены дифрактограммы области контакта, полученные до (1) и после (2) процесса эпитаксиального сращивания лент. Для проведения второго исследования был осуществлен разрыв соединенных лент. Видно, что во время соединения образуется небольшое количество „зеленой“ фазы $\mathrm{Y}_{2} \mathrm{BaCuO}_{5}$ и $\mathrm{CuO}$, что свидетельствует о частичном плавлении ҮВСО.

Методом ПРЭМ была исследована область контакта двух лент (рис. $3, b$ ). В результате твердофазной диффузии образуются области YBCO и GdYBCO, обеспечивающие протекание сверхпроводящего тока из одной ленты в другую. Видно, что $\mathrm{CuO}$ и $\mathrm{BaCuO}_{2}$ заполняют полости между пленками YВСО. 


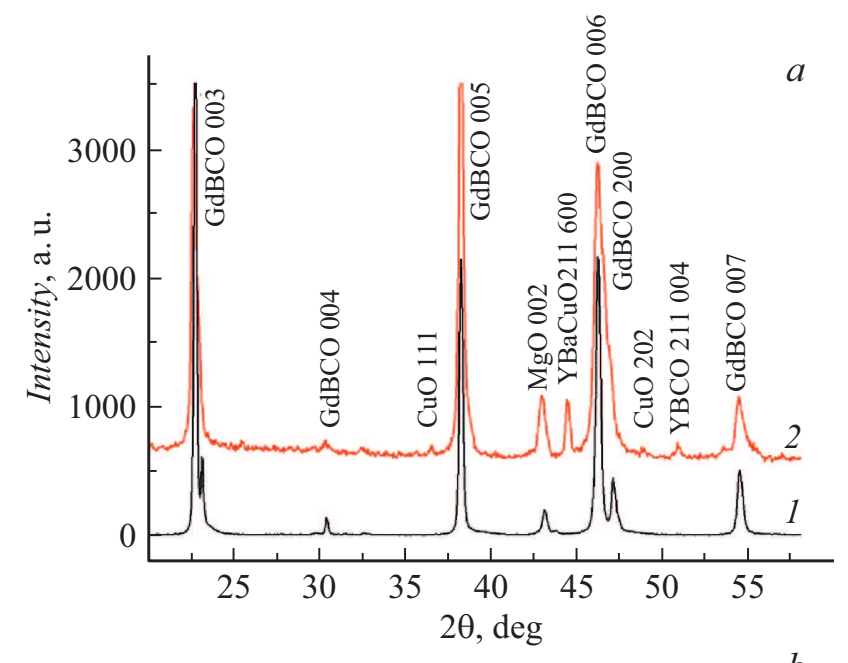

$b$

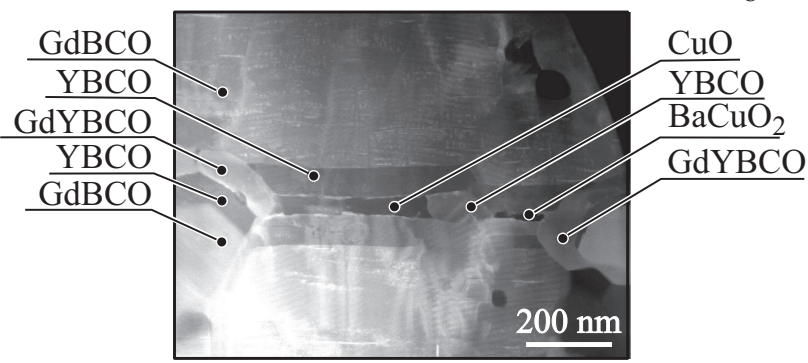

Рис. 3. $a$ - дифрактограммы ВТСП-ленты до (1) и после (2) процесса эпитаксиального сращивания; $b-$ ПРЭМ-изображение поперечного среза области контакта.

Таким образом, в работе предложен и реализован оригинальный подход для создания сверхпроводящего контакта двух ВТСП-лент второго поколения на основе GdBCO с использованием тонкого слоя YBCO, имеющего более низкую температуру плавления. Продемонстрировано значение критического тока сверхпроводящего контакта 18 А, что составляет более $30 \%$ от тока исходной ленты. Использование данного подхода позволяет провести соединение ВТСП-лент второго поколения без омического сопротивления, при этом не требуется дополнительной перфорации лент и многодневного отжига. Контакт имеет минимальные размеры, а сверхпроводящий тонкий слой ҮВСО формируется на том же оборудовании, что и основной сверхпроводящий слой GdBCO. Необходимы дальнейшие исследования для оптимизации условий сращивания лент с целью повышения токонесущей способности контакта, а также изучение скорости релаксации захваченного магнитного потока для определения перспектив использования данной технологии для создания магнитных систем с замороженным потоком.

Анализ экспериментальных образцов методами РСА и ПРЭМ проводился в Ресурсном центре лабораторных рентгеновских методов „РЕНТГЕН“ и Ресурсном центре зондовой и электронной микроскопии „НАНОЗОНД“ (Курчатовский комплекс НБИКС-природоподобных тех- нологий). Работа выполнена при финансовой поддержке гранта РФФИ № 17-29-10023 „офи_м“.

\section{Список литературы}

[1] Yao W., Bascunan J., Hahn S., Iwasa Y. // IEEE Transact. Appl. Supercond. 2009. V. 19. N 3. P. 2261-2264.

[2] Cheng J., Liu J., Ni Z., Cui C., Chen S., Song S., Li L., Dai Y., Wang Q. // IEEE Transact. Appl. Supercond. 2012. V. 22. N 2. P. 4300205.

[3] Park Y., Lee M., Ann H., Choi Y.H., Lee H. // NPG Asia Mater. 2014. V. 6. N 5. P. e98 (1-5).

[4] Park Y.J., Lee M.W., Oh Y.K., Lee H.G. // Supercond. Sci. Technol. 2014. V. 27. N 8. P. 085008 (1-9).

[5] Jin X., Yanagisawa Y., Maeda H., Takano Y. // Supercond. Sci. Technol. 2015. V. 28. N 7. P. 075010 (1-6).

[6] Zheng H., Jiang M., Nikolova R., Welp U., Paulikas A.P., Huang Y., Crabtree G.W., Veal B.W., Claus H. // Physica C. 1999. V. 322. N 1-2. P. 1-8.

[7] Iida K., Yoshioka J., Sakai N., Murakami M. // Physica C. 2002. V. 370. N 1. P. 53-58.

[8] Krylova T.S., Chernykh I.A., Chernykh M.Y., Krasnoperov E.P., Zanaveskin M.L. // Thin Solid Films. 2016. V. 598. P. 289-292.

[9] Kim H.S., Song J.B., Kwon N.Y., Kim K.L., Lee H.G. // Supercond. Sci. Technol. 2009. V. 22. N 12. P. 125016 (1-6). 